\title{
Is non-buffered DMEM solution a suitable medium for in vitro bioactivity tests?
}

Cite this: J. Mater. Chem. B, 2014, 2 , 5068

Received 4th February 2014 Accepted 15th May 2014

DOI: $10.1039 / \mathrm{c} 4 \mathrm{tb} 00187 \mathrm{~g}$

www.rsc.org/MaterialsB

\author{
Dana Rohanová, ${ }^{\text {*a }}$ Aldo Roberto Boccaccini, ${ }^{\mathrm{b}}$ Diana Horkavcová, ${ }^{a}$ \\ Pavlína Bozděchová, ${ }^{a}$ Petr Bezdička ${ }^{c}$ and Markéta Častorálovád
}

Several laboratories had tested bioactivity of the materials in commercially available solution DMEM (Dulbecco's Modified Eagle's Medium) that is normally used for cultivation of cell cultures. The objective of this work was to find out whether it is possible to replace TRIS-buffered SBF currently used for bioactivity tests with the non-buffered DMEM solution. To understand the role of the organic part of the DMEM solution in the process of crystallization, we have prepared non-buffered solution simulating only its inorganic part (identified as I-solution). It was found that under static-dynamic test conditions calcite $\left(\mathrm{CaCO}_{3}\right)$ and the amorphous phase of calcium phosphate (ACP) formed on the surface of the glassceramic (45S5 bioactive glass based) scaffold exposed to both solutions. Additionally, halite ( $\mathrm{NaCl}$ ) formed at the beginning of exposure to DMEM. Hydroxyapatite phase was not detected on the surface in either non-buffered solution. Organic components contained in the DMEM solution failed to prevent formation of crystalline phases. The present results indicate that it is not recommendable to use DMEM for bioactivity tests of glass-ceramic materials due to its low concentration of $\mathrm{Ca}^{2+}$ ions, high concentration of $\mathrm{HCO}_{3}{ }^{-}$ions and the necessity to maintain sterile environment during the test.

\section{Introduction}

The first tests usually performed on materials intended for substitution of hard tissues are bioactivity tests, i.e. tests monitoring the formation of a layer of biologically active hydroxyl carbonate apatite formed on the biomaterial surface. ${ }^{\mathbf{1}}$ Several preconditions need to be met for biomineralization (osseointegration) of the tested materials. The material must be dissolvable in blood serum (it must release $\mathrm{Ca}^{2+}$ ions or potentially also $\left(\mathrm{PO}_{4}\right)^{3-}, \mathrm{Na}^{+}$and $\mathrm{Si}$ ions in a controlled manner); "fresh" solution (blood serum) is supplied to the proximity of the material and bone mineral hydroxyapatite (HAp) may crystallize on it due to local supersaturation. The so-called simulated body fluid (SBF) has been used for bioactivity tests for many years. ${ }^{2}$ Unlike human blood serum, the original $\mathrm{SBF}^{3}$ contains no organic components; it has a higher content of $\mathrm{Cl}^{-}$ions and a lower content of $\mathrm{HCO}_{3}{ }^{-}$

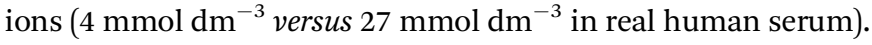
The $\mathrm{pH}$ of SBF is maintained at around 7.3 (at $37^{\circ} \mathrm{C}$ ) by using Tris

\footnotetext{
${ }^{a}$ Department of Glass and Ceramics, Faculty of Chemical Technology, Institute of Chemical Technology Prague, Technická 5, 16628 Prague 6, Czech Republic. E-mail: dana.rohanova@vscht.cz

${ }^{b}$ Department of Materials Science and Engineering, Institute of Biomaterials, University of Erlangen-Nuremberg, 91058 Erlangen, Germany

'Institute of Inorganic Chemistry of the ASCR, v.v.i., 25068 Husinec-Řež, Czech Republic

${ }^{d}$ Department of Biochemistry and Microbiology, Faculty of Food and Biochemical Technology, Institute of Chemical Technology Prague, Technická 3, 16628 Prague, Czech Republic
}

$\left(\mathrm{NH}_{2} \mathrm{C}\left(\mathrm{CH}_{2} \mathrm{OH}\right)_{3}\right)$, tris-[(hydroxymethyl)aminomethane]. In blood serum, the $\mathrm{pH}$ is partly buffered by hydrogen carbonate ions and by partial pressure of $\mathrm{CO}_{2}$. The $\mathrm{pH}$ value is critical for the formation of HAp. According to de Aza et al., ${ }^{4}$ the ideal $\mathrm{pH}$ for precipitation and crystallization of HAp is in the alkaline region $(\mathrm{pH}=7.5-8.0)$. However, during static and dynamic tests of dissolution of bioactive glasses, glass-ceramics and calciumphosphate materials (i.e. easily dissolving ones), the $\mathrm{pH}$ values in Tris-buffered SBF do not remain in the neutral area. Several hours after the material is exposed to SBF the $\mathrm{pH}$ value increases towards the alkaline region. This $\mathrm{pH}$ increase results in formation of an ideal, but not realistic, environment for HAp formation. Some authors have questioned whether bioactivity of materials can be predicted based only on development of a HAp layer on their surface after exposure to SBF., ${ }^{5,6}$ This is because SBF cannot simulate physiological conditions in a live organism completely but it only substitutes its analytical components (inorganic part of blood serum). Certainly it is justified to question if this information is sufficient for bioactivity assessment? Indeed for a first indication of potential bioactivity of biomaterials, it probably is. As we have found out in our previous work, ${ }^{7}$ Tris buffer, which is a part of SBF, reacts with the tested material (in our case with $45 \mathrm{~S} 5$ bioactive glass-derived glass-ceramic). We exposed the scaffold to a series of SBF solutions - Tris-buffered SBF, SBF without Tris, Tris alone and water. The Tris buffer supported dissolution of the crystalline phase of the glassceramic scaffold and it was the principal component for crystallization of the HAp phase. Moreover, $\mathrm{Ca}^{2+}$ ions bind with Tris 
buffer to form a soluble complex which had been described elsewhere ${ }^{8,9}$ and which may distort the results of in vitro tests.

Other authors ${ }^{3}$ have reported on preparation of SBF solutions whose concentrations of $\mathrm{HCO}_{3}{ }^{-}$are near to those in human blood serum ( $27 \mathrm{mmol} \mathrm{dm}^{-3}$ ) and, apart from approaching the real biological environment, they also anticipated an increased buffering ability of the inorganic part of SBF alone. However, all revised or modified SBF solutions still contain Tris buffer (revised (r-SBF), corrected (c-SBF) and newly improved (n-SBF)). The authors of ref. 10 and 11 used a modified SBF27 solution (concentration of $\mathrm{HCO}_{3}{ }^{-}$was $27 \mathrm{mmol} \mathrm{dm}^{-3}$ ) and demonstrated formation of carbonate hydroxyapatite (CHAp). In another investigation, ${ }^{12}$ collagen spongious Ap-CaP whiskers and $\mathrm{CaSO}_{4}$ doped with calcium hydrophosphate $\left(\mathrm{CaHPO}_{4}\right.$ monetite) were

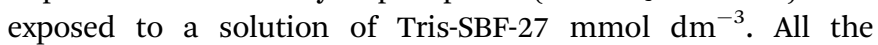
mentioned materials induced formation of nanoporous apatite in the solution, with the exception of $\mathrm{CaSO}_{4}$ alone, which crumbled in the solution into powder.

In a relevant investigation involving bioactive glasses, Cannillo et al. ${ }^{13}$ exposed two types of glasses (BG45 and MG45) not only to SBF but also to commercial solutions HBSS+ and HBSS-, designed for growing tissue cultures. HBSS solutions were not buffered with Tris but they differed in the contents of $\mathrm{Ca}$ and $\mathrm{Mg}$ ions. SBF solution was the most reactive one and it induced formation of apatite on the surface of BG45 glass in a shorter time than other solutions. The microstructure of the crystallized apatite on the BG45 glass was identical both in HBSS+ and in SBF. However, the reactivity (in the sense of apatite formation) was higher in SBF and this was explained by the authors in the presence of a higher concentration of $\mathrm{Ca}$ ions in $\mathrm{SBF}\left(1.4 \mathrm{mmol} \mathrm{dm}{ }^{-3} \mathrm{Ca}^{2+}\right.$ in HBSS+ compared to $2.5 \mathrm{mmol}$ $\mathrm{dm}^{-3}$ in SBF). A magnesium phosphate phase developed on the surface of MG45 glass in SBF which means that also glass significantly dissolved in SBF and that SBF was in this case supersaturated with respect to magnesium phosphate.

In other published articles, ${ }^{\mathbf{1 4 - 1 6}}$ attempts to substitute SBF with the commercially available DMEM solution, which is primarily designed for growing and maintaining tissue cultures, have been reported. The solution is available in many variants non-buffered or buffered with Tris, and with another buffer HEPES $\left(\mathrm{C}_{8} \mathrm{H}_{18} \mathrm{~N}_{2} \mathrm{O}_{4} \mathrm{~S}\right)$, 4-(2-hydroxyethyl) piperazine-1-ethanesulfonic acid, (Sigma Aldrich, Invitrogen GIBCO USA). Apart from the inorganic part of blood serum, this solution also contains the organic component. For example, Theodorou et $a l .{ }^{17}$ have found that as early as after three days of immersion in DMEM solution, the amorphous apatite phase developed at certain locations on silicate glass (Bioactive glass 45S5) and the carbonated crystalline apatite (CHAp) phase was found on $58 \mathrm{~S}$ glass. It was discussed that development of the CHAp crystalline phase is inhibited by the organic part of DMEM solution and the authors explained it by the effect of the adsorption of proteins on an amorphous Ca-P layer. ${ }^{17}$ However, it is not clear whether they used buffered or non-buffered DMEM solution which is critical for interpretation of the results. Miller et al. ${ }^{\mathbf{1 8}}$ studied the transformation of brushite into OCP (octacalcium phosphate) in various DMEM derived solutions. Solutions without organic phase did not have any $\mathrm{SO}_{4}{ }^{2-}$ ions and solutions with organic phases as lactic acid and Tris buffer contained $\mathrm{SO}_{4}{ }^{2-}$ ions. None of the solutions were able to maintain the $\mathrm{pH}$ at 7.4 , even during the first $24 \mathrm{~h}$. Brushite crystals were transformed into a biphasic mixture of OCP and CDHA (Ca-deficient HA), when soaked for 1 week in different biomineralization solutions at $37^{\circ} \mathrm{C}$. The authors also noticed that the extent of any hydrothermal transformation of DCPD into OCP and CDHA strongly depended on the overall dimensions or thicknesses (sizes) of the samples. Temizel et al. ${ }^{19}$ used derived solutions of DMEM buffered with HEPES and solution marked as BM-3 non-buffered with HEPES. When HEPES was eliminated in BM-3, it became possible for the first time to completely convert the DCPD crystals to OCP in less than $72 \mathrm{~h}$ at $36.5^{\circ} \mathrm{C}$. The effect of the presence of HEPES could be due to the complexation of some of the $\mathrm{Ca}^{2+}$ ions of the solution by the HEPES buffer at the $\mathrm{Ca} / \mathrm{P}$ molar ratio of 1.99 and could reduce the concentration of free $\mathrm{Ca}^{2+}$ ions available for the DCPD to OCP transformation. The experimental results showed that increasing the temperature from $55{ }^{\circ} \mathrm{C}$ to $60{ }^{\circ} \mathrm{C}$ in a $1 \mathrm{~h}$ stirred experiment increased the possibility of obtaining apatite-CaP mainly due to the high solubility of DCPD. The optimum temperature required to achieve a complete transformation to OCP crystals was $75-80{ }^{\circ} \mathrm{C}$. Evidently, the type of used solution, buffering system and the arrangement of the test (e.g. S/V) and temperature are very important for the interpretation of obtained results.

The purpose of this research was to study the suitability of non-buffered DMEM solution for bioactivity testing, considering its reduced concentration of $\mathrm{Ca}^{2+}$ and high concentration of $\mathrm{HCO}_{3}{ }^{-}$ions, the fact that it contains organic components of blood serum and, unlike SBF, it is not buffered with Tris.

\section{Materials and methods}

\subsection{Materials}

The material used for testing was silicate glass-ceramic in the form of a highly porous structure (scaffold) prepared by the foam replica technology. ${ }^{\mathbf{2 0}}$ The initial material for preparation of a glass suspension was 45S5 bioactive glass (45S5 BG) powder with a mean particle size $<5 \mu \mathrm{m}$. For scaffold preparation the polyurethane (PUR) foam was immersed into the prepared suspension, it was taken out 15 minutes later and the excessive suspension was squeezed out. The created porous precursors, the so-called green bodies, were left to dry for 12 hours at room temperature and were then subjected to thermal treatment consisting of firing at $400{ }^{\circ} \mathrm{C}$ per 1 hour to burn-out the PUR template and further sintering at $1100{ }^{\circ} \mathrm{C}$ for 5 hours. $^{20}$ The scaffold had an open porous structure with the pore size in the range of $510-720 \mu \mathrm{m}$ and porosity of approximately $90 \%$. The material contained crystalline and residual glass phases. Their contents before and after the crystallization, according to a previous publication, ${ }^{20}$ are shown in Table 1.

\subsection{Solutions for the in vitro test}

The modified simulated body fluid with reduced concentration of $\mathrm{Ca}^{2+}$ ions and increased concentration of $\mathrm{HCO}_{3}{ }^{-}$ions to 
$44 \mathrm{mmol} \mathrm{dm}^{-3}$ (I-solution) was prepared by mixing solutions of the following reagents: $\mathrm{KCl}, \mathrm{NaCl}, \mathrm{NaHCO}_{3}, \mathrm{MgCl}_{2} \cdot 6 \mathrm{H}_{2} \mathrm{O}$, $\mathrm{CaCl}_{2}, \mathrm{Na}_{2} \mathrm{SO}_{4}$ and $\mathrm{KH}_{2} \mathrm{PO}_{4}$ in respective ratios. Azide $\left(\mathrm{NaN}_{3}\right)$ was added to prevent bacterial growth in the solution. ${ }^{7,21} \mathrm{I}-$ solution was not buffered and the $\mathrm{pH}$ value was not adjusted.

Dulbecco's Modified Eagle's Medium (DMEM) is normally used to grow tissue culture and it simulates the environment of the human body because, in addition to inorganic ions, it also contains organic substances, such as amino acids, glucose and vitamins. A modified DMEM (mod-DMEM) was prepared for testing in this study by enriching the standard DMEM (D1145, Sigma-Aldrich) with fetal bovine serum (FBS, Invitrogen), vitamins (MEM, Invitrogen) and antibiotics (Sigma-Aldrich), A5955 Sigma Antibiotic Antimycotic solution $(100 \times)$ stabilized with 10000 units penicillin, $10 \mathrm{mg}$ streptomycin and $25 \mu \mathrm{g}$ amphotericin B per $\mathrm{mL}$, sterile-filtered, BioReagent.

The reason for the FBS and vitamin addition was to enrich the organic part of the DMEM. Antibiotics protect prepared solution against degradation during the test. Table 2 presents the ion composition of I-solution and the inorganic part of modDMEM in comparison with blood plasma (BP), as published in the literature, ${ }^{22}$ the $\mathrm{Ca} / \mathrm{P}$ molar ratio is presented.

\subsection{Static-dynamic conditions of the in vitro test}

To prevent the effect of exhaustion of ions from the solutions, the so-called static-dynamic test was carried out in which, although the testing solutions did now flow continually around the sample as in dynamic tests, the solution was replaced on a daily basis (50 $\mathrm{ml}$ per day), i.e. every 24 hours. The scaffolds used for the static-dynamic arrangement of the in vitro test had an average weight in the range of $0.045-0.055 \mathrm{~g}$, they were placed in platinum spirals and suspended in $50 \mathrm{ml}$ plastic bottles filled with I-solution or mod-DMEM. The bottles with the samples were placed into a thermostat maintaining the temperature at $36.5 \pm 0.5{ }^{\circ} \mathrm{C}$. The interaction time was 15 days and two samples were collected in selected time intervals (after 1, 3, 7, 11 and 15 days), rinsed with demineralized water and left to dry at laboratory temperature. In order to maintain a sterile environment the replacement of the mod-DMEM solution was performed in a "flow box".

\subsection{Analysis of the materials}

2.4.1. Scanning electron microscopy/energy-dispersive spectroscopy (SEM/EDS). The surface of tested materials before and after the immersion tests was inspected with a Hitachi
S-4700 scanning electron microscope (SEM) equipped with an EDS analyzer (NORAN D-6823) working at an accelerating voltage of $15 \mathrm{kV}$. The samples were powder coated with an $\mathrm{Au}-\mathrm{Pd}$ layer during 80-100 s for SEM observations.

2.4.2. X-ray powder diffraction analysis. Samples were ground in an agate mortar in a suspension with cyclohexane. The suspension was then placed on a mylar film and fixed to a transmission sample holder. After solvent evaporation a thin layer of the prepared sample was covered with another mylar film. The diffraction patterns were collected using a PANalytical X'Pert PRO diffractometer equipped with a conventional X-ray tube $\left(\mathrm{Cu}_{\mathrm{K} \alpha} 40 \mathrm{kV}, 30 \mathrm{~mA}\right.$, line focus) working in transmission mode. An elliptic focusing mirror with divergence slit $0.5^{\circ}$, an anti-scatter slit $0.5^{\circ}$ and a soller slit of 0.02 rad were used in the primary beam. A fast linear position sensitive detector PIXcel with an anti-scatter shield and a soller slit of 0.02 rad was used in the diffracted beam. All patterns were collected in the range of 3 to $88 \mathrm{deg}$. 2 theta with the step of $0.013 \mathrm{deg}$ and $600 \mathrm{~s}$ per step producing a scan of about 4.5 hours. Qualitative analysis was performed with a HighScorePlus software package (PANalytical, The Netherlands, version 3.0e), a Diffrac-Plus software package (Bruker AXS, Germany, version 8.0) and JCPDS-ICDD PDF-2 database. ${ }^{23}$

\subsection{Leachate analysis}

All tests and analyses were performed using two parallel series of samples.

2.5.1. Atomic absorption spectrophotometry. Concentrations of $\mathrm{Ca}^{2+}$ ions were analyzed in leachates from both types of solutions with a VARIAN-SpectrAA 300. The so-called release agent $(\mathrm{KCl})$ was added to each sample to determine the quantity of $\mathrm{Ca}$. The leachate was atomized in acetylene- $\mathrm{N}_{2} \mathrm{O}$ flame. The wavelength used for absorbance measurements was $422.7 \mathrm{~nm}$. Concentrations of Si were analyzed in leachates from both types of solutions with a VARIAN-SpectrAA 880. The leachates were atomized in acetylene- $\mathrm{N}_{2} \mathrm{O}$ flame. The wavelength used for absorbance measurements was $251.6 \mathrm{~nm}$.

2.5.2. Spectrophotometry. Concentrations of $\left(\mathrm{PO}_{4}\right)^{3-}$ ions were analyzed in I-solution leachates with a UV-Vis spectrophotometer UV1601 at wavelength $830 \mathrm{~nm}$ (ČSN 830540). Ion concentrations were calculated using a calibration line method from the measured absorbance values.

2.5.3. Inductively coupled plasma-optical emission spectroscopy (ICP-OES). Concentrations of P in mod-DMEM leachates were measured by ICP-OES with a Perkin Elmer-Optima

Table 1 Composition of 4555 BG, crystalline and glass phases ${ }^{20}$

\begin{tabular}{llll}
\hline Oxides & $45 \mathrm{~S} 5 \mathrm{BG}(100 \mathrm{wt} \%)$ & $\mathrm{Na}_{2} \mathrm{Ca}_{2} \mathrm{Si}_{3} \mathrm{O}_{9}(77.4 \mathrm{wt} \% \text { scaffold })^{a}$ & Residual glass phase (22.6 wt\% scaffold) \\
\hline $\mathrm{SiO}_{2}$ & 45.0 & 50.9 & 24.8 \\
$\mathrm{Na}_{2} \mathrm{O}$ & 24.5 & 17.4 & 48.5 \\
$\mathrm{CaO}$ & 24.5 & 31.7 & - \\
$\mathrm{P}_{2} \mathrm{O}_{5}$ & 6.0 & - & 26.5
\end{tabular}

${ }^{a}$ The minority crystalline phases $\mathrm{CaO} \cdot \mathrm{SiO}_{2}$ and $\mathrm{NaCaPO}_{4}$ (buchwaldite) are included. 
Table 2 Ion composition ( $\mathrm{mmol} \mathrm{dm}{ }^{-3}$ ) of mod-DMEM, I-solution $\mathrm{BP}^{22} \mathrm{SBF}^{22}$ and $\mathrm{Ca} / \mathrm{P}$ molar ratio

\begin{tabular}{|c|c|c|c|c|c|c|c|c|c|}
\hline & $\mathrm{Na}^{+}$ & $\mathrm{K}^{+}$ & $\mathrm{Ca}^{2+}$ & $\mathrm{Mg}^{2+}$ & $\mathrm{Cl}^{-}$ & $\mathrm{HCO}_{3}{ }^{-}$ & $\mathrm{HPO}_{4}{ }^{2-}$ & $\mathrm{SO}_{4}{ }^{2-}$ & $\mathrm{Ca} / \mathrm{P}$ \\
\hline mod-DMEM & 154.5 & 5.4 & 1.8 & 0.8 & 118.5 & 44.0 & 0.9 & 0.8 & 1.97 \\
\hline I-solution & 142.0 & 5.0 & 1.8 & 1.0 & 91.6 & 44.0 & 1.0 & 0.5 & 1.80 \\
\hline SBF orig. & 142.0 & 5.0 & 2.5 & 1.0 & 148.8 & 4.2 & 1.0 & 0.0 & 2.50 \\
\hline
\end{tabular}

2000DV instrument. The solution was vaporized with a GemConeTM nebulizer and the flow rate of the solution through the

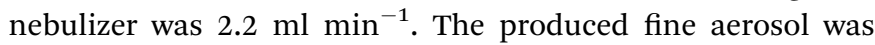
carried with an argon stream into a plasmatic burner $(1300 \mathrm{~W})$. The concentrations were measured at wavelengths 231.620, 214.917 and $178.221 \mathrm{~nm}$.

2.5.4. pH measurement. $\mathrm{pH}$ values in I-solution and modDMEM leachates were measured with an inoLab pH-meter with a combined glass electrode at laboratory temperature.

\section{Results}

\subsection{Interaction of scaffolds with mod-DMEM}

3.1.1. Leachate analysis of mod-DMEM during interaction with the scaffold. Fig. $1 \mathrm{a}$ and $\mathrm{b}$ show concentrations of $\mathrm{Ca}^{2+}$ and $\left(\mathrm{PO}_{4}\right)^{3-}$ and $\mathrm{pH}$ in mod-DMEM leachates after the scaffold exposure. The leachate analysis suggests that potential processes of scaffold dissolution and precipitation of new phases occurred at a stable rate practically throughout the entire duration of the experiment. Concentrations of $\left(\mathrm{PO}_{4}\right)^{3-}$ ions after 7 days of interaction slightly increased which means that the process of scaffold dissolution started prevailing over the precipitation of new phases. ICP could not be used to determine concentrations of $\mathrm{Si}$ (which is a "marker" for scaffold dissolution) in mod-DMEM leachates, because of the high error of the measurement of the samples with low concentration of $\mathrm{Si}$ (1-10 $\mathrm{mg} \mathrm{dm}^{-3}$ ). The mod-DMEM solution was not buffered and the $\mathrm{pH}$ value increased from 7.45 to 8.90 soon after the beginning of the exposure and it oscillated at around $\mathrm{pH} 8.90$ until the end of the test (Fig. 1b). The pH changes can be considered an indicator of ongoing processes of dissolution and precipitation during scaffold exposure to mod-DMEM.

3.1.2. X-ray powder diffraction analysis of scaffolds before and after interaction with mod-DMEM. Records from XRD powder diffraction analysis of the scaffold before and after 3, 7, 11 and 15 days of interaction with mod-DMEM are shown in Fig. 2.

$\mathrm{XRD}$ analysis before the exposure confirmed the presence of the main crystalline phase $\mathrm{Na}_{2} \mathrm{O} \cdot 2 \mathrm{CaO} \cdot 3 \mathrm{SiO}_{2}$ (combeite) and two minority structurally isomorphic phases $\mathrm{CaO} \cdot \mathrm{SiO}_{2}$ and $\mathrm{NaCaPO}_{4}$ (buchwaldite) in the original scaffold (Fig. 2). Crystalline phases of $\mathrm{NaCl}$ (halite) and $\mathrm{CaCO}_{3}$ (calcite) developed after three days of exposure (3D). The intensity of diffraction lines for the halite phase decreased with increasing interaction time (7-15D) and, in contrast, it increased for the calcite phase. The XRD diffractograms indicate the growth of a nanocrystalline phase (indicated in the diffractogram as a broad diffusion maximum) approximately from the $7^{\text {th }}$ day of the test. It is probably a phase consisting of a mixture of nanocrystallineamorphous calcium phosphate (ACP), which has been also discussed in the literature for immersion in SBF. ${ }^{7}$ The intensity of the original crystalline phases of the scaffold remained practically unchanged which means that they did not dissolve in the mod-DMEM solution.

3.1.3. SEM/EDS characterization of scaffolds before and after interaction with mod-DMEM. Changes on the surface of the scaffolds after 3, 7, 11, 15 days of interaction with modDMEM can be seen in the SEM images (Fig. 3b-e) and EDS analyses (indicative measurement) are provided in Table 3. The original morphology of the scaffold surface is shown in Fig. 3a.

Fig. 3a shows the surface of the original scaffold with small tabular crystals of combeite and needle like crystals, likely corresponding to buchwaldite as well as to the structural isomorphic phase $\mathrm{CaO} \cdot \mathrm{SiO}_{2}$. The SEM/EDS analysis confirmed that as early as after three days (3D) the scaffold surface was
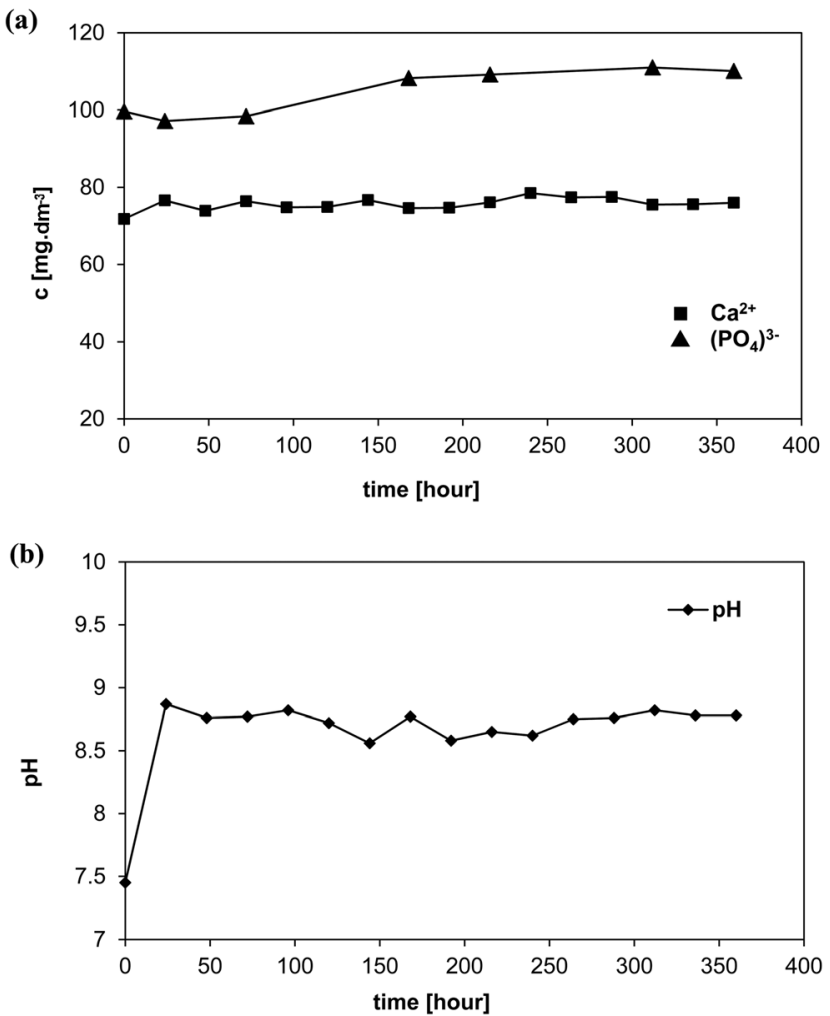

Fig. 1 Concentrations of (a) $\mathrm{Ca}^{2+}$ and $\left(\mathrm{PO}_{4}\right)^{3-}$ ions and (b) values of $\mathrm{pH}$ in mod-DMEM during interaction with scaffolds. 


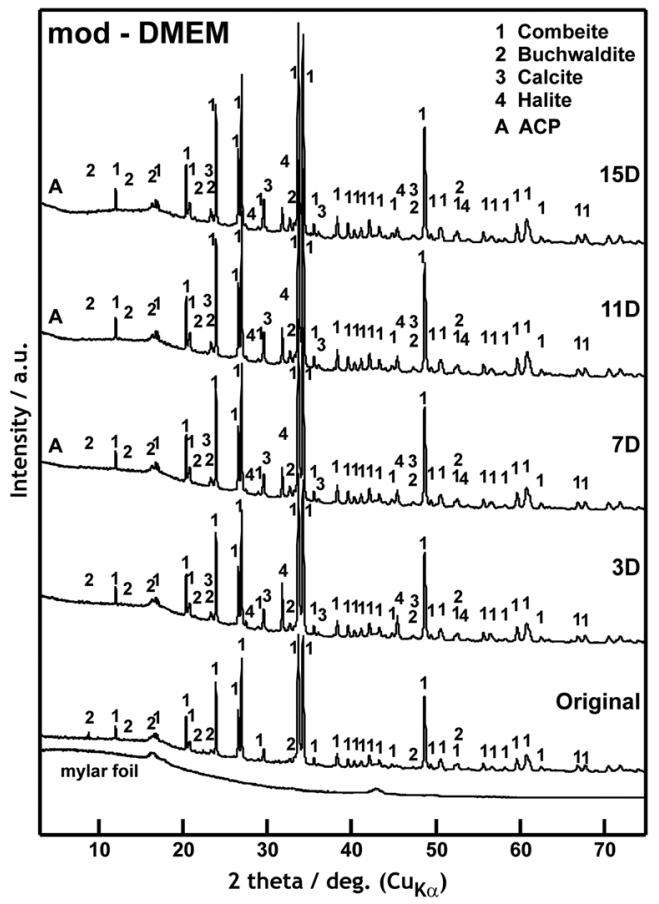

Fig. 2 XRD patterns of the scaffold before and after 3, 7, 11 and 15 days of interaction with mod-DMEM.

covered with ACP (amorphous calcium phosphate) (growing content of $\mathrm{Ca}$ and $\mathrm{P}$ ) and $\mathrm{NaCl}$ (Table 3, Fig. 3b, white crystal, $1 \mu \mathrm{m}$ in size), which is in agreement with the XRD analysis (Fig. 2). A phase with a high content of Ca developed after one week (7D) (by XRD diffraction detected as $\mathrm{CaCO}_{3}$ ) and it can be seen in images from SEM/EDS as white $1 \mu \mathrm{m}$ globules (Fig. 3c). After 11 days (11D) the phase with a high Ca content started prevailing and quantities of $\mathrm{Na}$ and $\mathrm{Cl}$ on the scaffold surface gradually decreased. The content of $\mathrm{P}$ remained unchanged after the third day of interaction. At the end of the test (15D) the scaffold surface was mostly covered with a phase having a high content of $\mathrm{Ca}$ (according to $\mathrm{XRD}-\mathrm{CaCO}_{3}$, Fig. 2) and with a cauliflower-like structure (Fig. 3e and f) and also ACP was detected on scaffold surfaces. The results of SEM/EDS measurements were therefore in good agreement with the XRD analysis.

\subsection{Interaction of scaffolds with I-solution}

3.2.1. Leachate analysis of I-solution during interaction with the scaffold. Analyses of the I-solution leachates showed that the scaffold significantly dissolved immediately after exposure to the medium, which was well-documented by the presence of $\mathrm{Si}$ in the leachates (Fig. 4a). 48 hours after the beginning of exposure the rates of scaffold dissolution and precipitation of the Ca-P phase stabilized, as documented by concentrations of $\mathrm{Ca}^{2+}$ and $\left(\mathrm{PO}_{4}\right)^{3-}$ ions (Fig. $4 \mathrm{~b}$ ). The decrease of $\mathrm{Ca}^{2+}$ and $\left(\mathrm{PO}_{4}\right)^{3-}$ concentrations indicates the precipitation of the Ca-P phase. The $\mathrm{pH}$ value of non-buffered I-solution was 8.50 at the beginning and, due to scaffold dissolution and
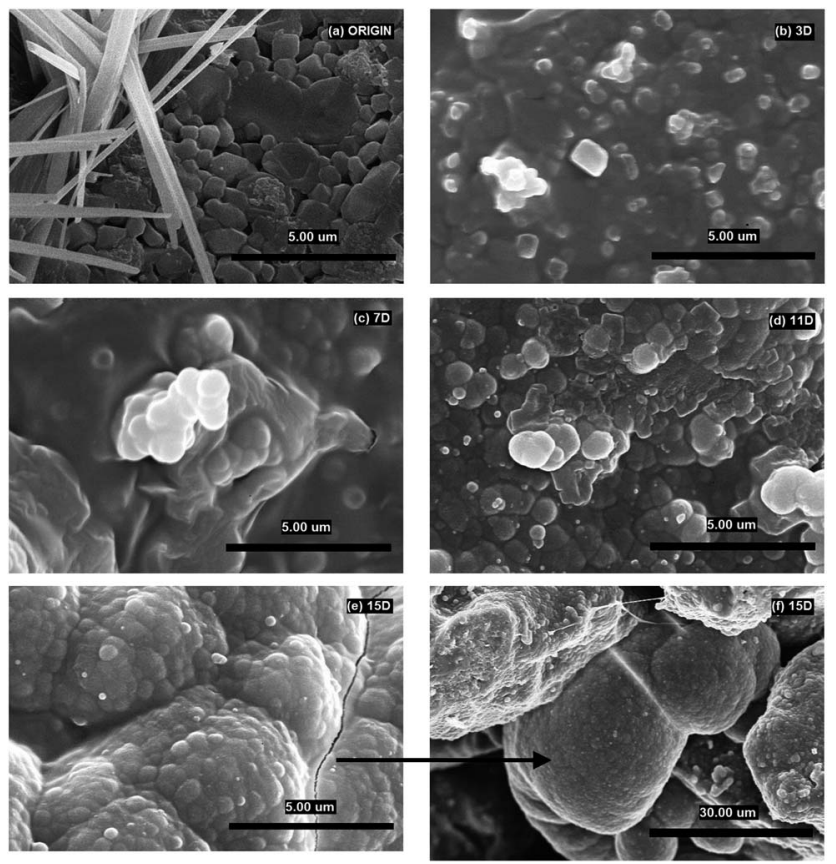

Fig. 3 SEM images of scaffolds (a) before (combeite - the small tabular crystals, buchwaldite and structurally isomorphic phase $\mathrm{CaO} \cdot \mathrm{SiO}_{2}$ - needle-like crystals) and after (b) 3, (c) 7, (d) 11, and (e and f) 15 days of interaction with mod-DMEM.

formation of the new phase, it increased to 9.20 and remained around that value until the end of the test (Fig. 4c).

3.2.2. Si as a dissolution "marker". The concentrations of $\mathrm{Si}$ in I-solution leachates made it possible to calculate quantities of the dissolved scaffold. The calculation was also possible owing to the conditions of the static-dynamic test as it was possible to use the current concentration of Si in a known volume of leachate (every day precisely $50 \mathrm{ml}$ ) to calculate the quantity of leached $\mathrm{SiO}_{2}$. The total quantity of leached $\mathrm{SiO}_{2}$ was subsequently converted to the weight of the dissolved scaffold, based on an assumption that $\mathrm{SiO}_{2}$ represents 45 weight $\%$ of the scaffold. The fact that the leached $\mathrm{SiO}_{2}$ originated both from the crystalline and glass phases was neglected for reasons of simplification (the crystalline phase contains $c a .7 \times$ more $\mathrm{SiO}_{2}$ than the residual glass phase). Thus assuming that the dissolution rates are identical for both scaffold phases our calculations indicate that $7.2 \mathrm{mg}$ of $\mathrm{SiO}_{2}$ leached in total from ca. $55 \mathrm{mg}$ of the exposed sample. This means that $c a .16 \mathrm{mg}$ of scaffold dissolved in 15 days of exposure to the I-solution, i.e. approximately $1 / 3$ of the initial weight of the tested scaffold. If the dissolved phase had been only the residual glass phase it would have dissolved completely. We also tried to calculate quantities of dissolved $\mathrm{Ca}$ and $\mathrm{P}$, however, due to their re-precipitation and formation of several different phases on the scaffold surface the calculation would be very complicated and indeed quantitatively inaccurate.

3.2.3. X-ray powder diffraction analysis of scaffolds before and after interaction with I-solution. Records from XRD powder diffraction analysis of the scaffold before and after 1, 3, 7, 11 and 15 days of interaction with I-solution are shown in Fig. 5. 
Table 3 Chemical and crystalline composition of the original scaffold surface and the surface after its exposure to mod-DMEM [wt\%] (by SEM/ EDS)

\begin{tabular}{|c|c|c|c|c|c|c|c|c|c|}
\hline Time [days] & $\mathrm{O}$ & $\mathrm{Na}$ & $\mathrm{Mg}$ & $\mathrm{Si}$ & $\mathrm{P}$ & $\mathrm{Cl}$ & K & $\mathrm{Ca}$ & Probable phases $^{a}$ \\
\hline Origin & 39.4 & 20.3 & - & 20.9 & 1.6 & - & - & 17.9 & $\mathrm{Na}_{2} \mathrm{Ca}_{2} \mathrm{Si}_{3} \mathrm{O}_{9}$ \\
\hline $3 \mathrm{D}$ & 45.2 & 10.9 & 2.1 & 2.6 & 6.4 & 6.6 & 1.0 & 25.1 & $\mathrm{ACP}, \mathrm{NaCl}$ \\
\hline $7 \mathrm{D}$ & 37.3 & 9.8 & 1.3 & 5.8 & 3.7 & 7.3 & 0.7 & 34.2 & $\mathrm{NaCl}, \mathrm{ACP}, \mathrm{CaCO}_{3}$ \\
\hline $11 \mathrm{D}$ & 40.9 & 3.8 & 0.9 & 8.7 & 4.2 & 3.3 & 1.0 & 37.2 & $\mathrm{CaCO}_{3}, \mathrm{ACP}, \mathrm{NaCl}$ \\
\hline $15 \mathrm{D}$ & 45.5 & 2.4 & 1.5 & 3.5 & 5.5 & 1.5 & 0.3 & 39.9 & $\mathrm{CaCO}_{3}, \mathrm{ACP}$ \\
\hline
\end{tabular}

${ }^{a}$ Combeite: $\mathrm{Na}_{2} \mathrm{Ca}_{2} \mathrm{Si}_{3} \mathrm{O}_{9}$, halite: $\mathrm{NaCl}$, calcite: $\mathrm{CaCO}_{3}$, ACP: amorphous calcium phosphate.
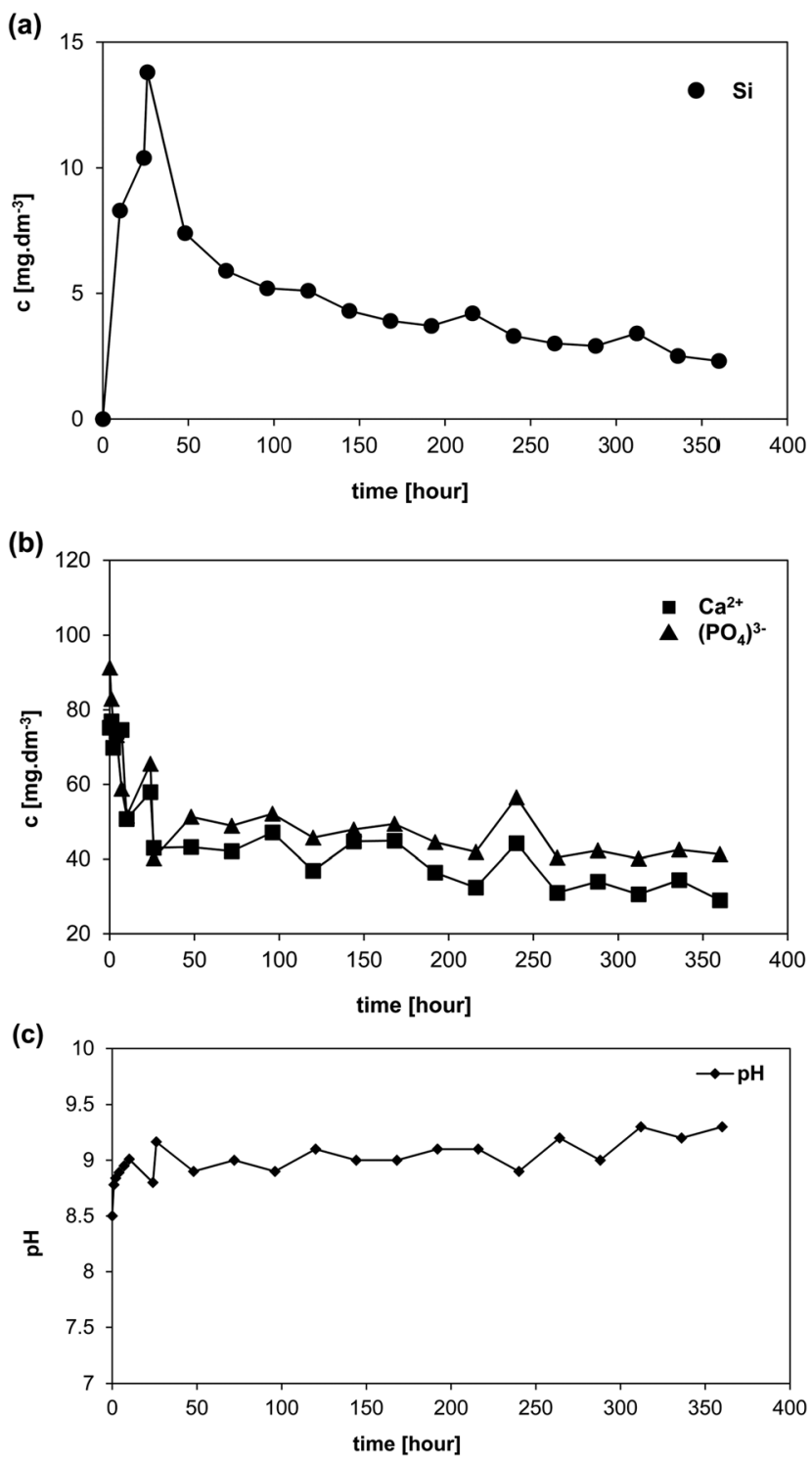

Fig. 4 Concentrations of (a) $\mathrm{Si}$ and (b) $\mathrm{Ca}^{2+}$ and $\left(\mathrm{PO}_{4}\right)^{3-}$ ions and (c) values of $\mathrm{pH}$ in I-solution during interaction with scaffolds.

XRD diffraction confirmed formation of a calcite crystalline phase $\left(\mathrm{CaCO}_{3}\right)$ as early as after the first day (1D) of exposure to Isolution (Fig. 5). After three days of exposure (3D), an increase in the content of the amorphous phase ACP (Amorphous Calcium Phosphate) was recorded. No formation of the HAp phase was observed, not even after 15 days of exposure to Isolution. No halite $(\mathrm{NaCl})$ was formed either, probably due to lower concentrations of $\mathrm{Na}^{+}$and $\mathrm{Cl}^{-}$ions in the I-solution in comparison to mod-DMEM. The original phases of the scaffold are visible in the XRD patterns until the end of the test (0-15D). We assume that the main dissolved phase of glass-ceramic was the residual glass phase of the scaffold.

3.2.4. SEM characterization of scaffolds before and after interaction with I-solution. Changes on the scaffold surface after 1, 3, 7, 11, 15 days of interaction with I-solution are shown in Fig. 6b-f. The scaffold surface before the interaction is shown in Fig. 6a.

Fig. $6 \mathrm{~b}-\mathrm{f}$ and results of EDS analyses in Table 4 confirm conclusions from XRD analysis. Well-developed globules of $\mathrm{CaCO}_{3}$ (Fig. 6b) with the diameter of $c a .1 \mu \mathrm{m}$ were visible from

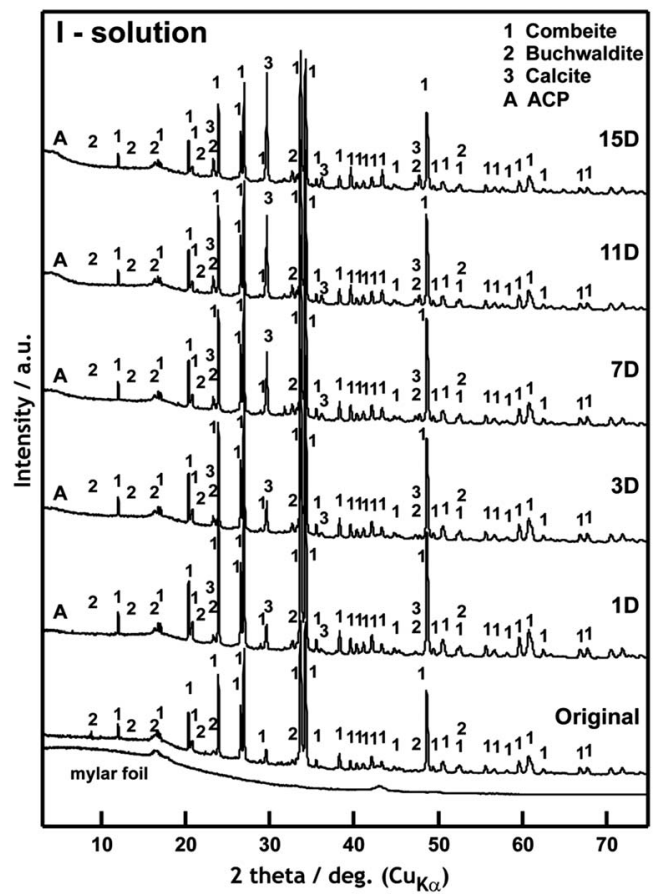

Fig. 5 XRD patterns of scaffolds before and after 1, 3, 7, 11 and 15 days of interaction with I-solution. 
the very beginning of the interaction (1D). It was the same phase that developed on the scaffold surface exposed to mod-DMEM. Apart from the growth and agglomeration of the globules (3D) (Fig. 6c), there was a significant growth of the ACP phase (715D) (Fig 6d), which has been also detected for immersion in $\mathrm{SBF}^{7} \mathrm{NaCl}$ was not detected, neither with XRD nor with SEM/ EDS. $\mathrm{CaCO}_{3}$ globules covered by the ACP phase formed in Isolution looked like hydroxyapatite at the first sight but XRD analysis failed to confirm the presence of the HAp crystalline phase.

\section{Discussion}

Analyses of leachates from 45S5 BG-based glass-ceramic scaffolds immersed in non-buffered mod-DMEM and non-buffered I-solutions showed that $\mathrm{pH}$ values in those systems (because of enormous dissolution of the tested scaffold) increased far into the alkaline area (up to $\mathrm{pH}$ 9). We assume that at such $\mathrm{pH}$ values the residual glass phase, which functions as a "binding agent" in the glass-ceramic material, will significantly dissolve. This fact has been confirmed by practical experience from the test as the glass-ceramic material in non-buffered I-solution (but also in mod-DMEM) disintegrated. XRD measurements after 15 days of exposure in both cases confirmed the presence of the original crystalline phases of the scaffold. The results indicate therefore that the high concentration of $\mathrm{HCO}_{3}{ }^{-}$ions (DMEM contains approx. $160 \% \mathrm{HCO}_{3}{ }^{-}$(s) of that in human plasma) coupled with $\mathrm{CO}_{2}(\mathrm{~g})$ from air does not have sufficient buffering capacity in the tested solutions. The DMEM solution fails to contain
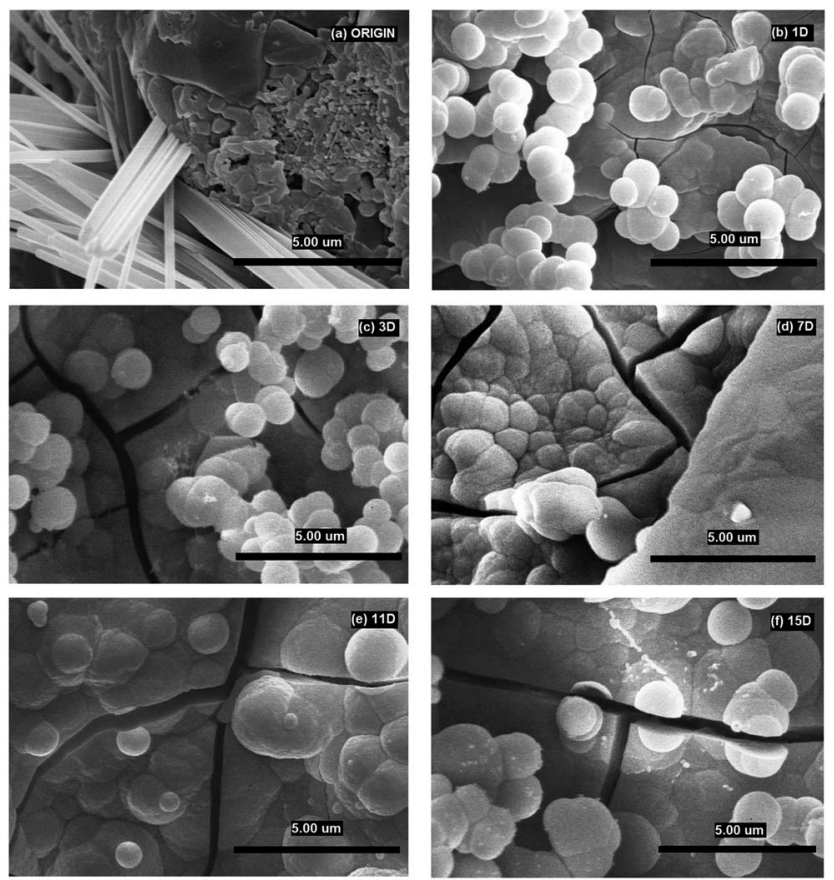

Fig. 6 SEM images of scaffolds (a) before (combeite - the small tabular crystals, buchwaldite and structurally isomorphic phase $\mathrm{CaO} \cdot \mathrm{SiO}_{2}$ - needle-like crystals) and after (b) 1, (c) 3, (d) 7, (e) 11 and (f) 15 days of interaction with I-solution. The fractures in the newly developed layers were caused by drying of samples.
Table 4 Chemical and crystalline composition of the original scaffold surface and the surface after the interaction with I-solution [wt\%] (SEM/EDS)

\begin{tabular}{lcrcrccl}
\hline Time [day] & $\mathrm{O}$ & $\mathrm{Na}$ & $\mathrm{Mg}$ & \multicolumn{1}{c}{$\mathrm{Si}$} & $\mathrm{P}$ & $\mathrm{Ca}$ & Probable phase \\
\hline Origin & 43.5 & 22.8 & & 17.1 & 0 & 16.6 & $\mathrm{Na}_{2} \mathrm{Ca}_{2} \mathrm{Si}_{3} \mathrm{O}_{9}$ \\
1D & 44.2 & 4.9 & 2.0 & 8.2 & 5.2 & 35.4 & $\mathrm{Na}_{2} \mathrm{Ca}_{2} \mathrm{Si}_{3} \mathrm{O}_{9}$ \\
& & & & & & & $\mathrm{ACP}_{2} \mathrm{CaCO}_{3}$ \\
3D & 36.1 & 1.6 & - & 2.0 & 4.4 & 56.0 & $\mathrm{ACP}, \mathrm{CaCO}_{3}$ \\
7D & 49.8 & 2.5 & 2.8 & 3.1 & 6.9 & 34.9 & $\mathrm{ACP}, \mathrm{CaCO}_{3}$ \\
11D & 45.5 & 2.6 & 2.7 & - & 7.0 & 42.2 & $\mathrm{ACP}, \mathrm{CaCO}_{3}$ \\
15D & 41.6 & 2.6 & 3.5 & 3.0 & 5.5 & 43.7 & $\mathrm{ACP}, \mathrm{CaCO}_{3}$
\end{tabular}

${ }^{a}$ Combeite: $\mathrm{Na}_{2} \mathrm{Ca}_{2} \mathrm{Si}_{3} \mathrm{O}_{9}$, calcite: $\mathrm{CaCO}_{3}$, ACP: amorphous calcium phosphate.

sufficient quantity of $\mathrm{Ca}^{2+}$ ions (only $70 \%$ of that in human serum) and the $\mathrm{Ca} / \mathrm{P}$ molar ratio is near 2 in contrast to human plasma (2.5). Such an environment is not supersaturated with respect to HAp but, it is preferentially supersaturated with respect to the amorphous calcium phosphate phase and $\mathrm{CaCO}_{3}$.

After being exposed to both investigated solutions the newly formed crystalline phase on the surface of scaffolds was mainly calcite $\left(\mathrm{CaCO}_{3}\right)$ (shaped into globules). In our previous study, ${ }^{7}$ we discussed that a visually identical phase that formed in SBF without Tris buffer was amorphous ACP, and even after conducting XRD analysis we were not able to prove the presence of $\mathrm{CaCO}_{3}$ after the scaffold exposure to SBF without Tris. The quantity of $\mathrm{CaCO}_{3}$ was very low and the most intense lines for $\mathrm{CaCO}_{3}$ overlapped with diffraction lines of the main crystalline phase of the as-fabricated scaffold; i.e. combeite. However, we have to take into account, that solution SBF without Tris from our previous experiment had the concentration of $\mathrm{HCO}_{3}{ }^{-}$ions more than 10-times lower opposite to I-solution or mod-DMEM used here. Based on the findings described above it is possible to expand our knowledge on the in vitro behavior of these particular 45S5 BG-derived scaffolds. In this study we found that the amorphous phase containing $\mathrm{Ca}$ and $\mathrm{P}(\mathrm{ACP})$ precipitated in both tested solutions on the scaffold surface, as it was anticipated on the grounds of consumed $\mathrm{Ca}$ and $\mathrm{P}$ in the non-buffered I-solution leachates. In both cases the phase was detected owing to the increased quantity of phosphorus on the sample surface as detected by EDS. The presence of ACP was also confirmed by the XRD results (the share of the amorphous phase increased with the time of scaffold exposure to the solutions). The ACP phase is probably in the form of nanospheres covering the $\mathrm{CaCO}_{3}$ globules. Later, the amorphous phase can transform into OCP crystals. ${ }^{24}$ As also shown in our recent study, ${ }^{25}$ crystallization of $\mathrm{CaCO}_{3}$ on the glass-ceramic surface in the non-buffered DMEM derived solution with concentration of $\mathrm{HCO}_{3}{ }^{-}$ions near to those of human plasma $\left(27 \mathrm{mM} \mathrm{dm}^{-3}\right.$ ) will prevail. Moreover, ACP was also found in 27SBF solution (without buffer Tris). ${ }^{25}$

We have not found evidence that the organic part of nonbuffered mod-DMEM suppresses crystallization of phases, as calcite crystallized on the scaffold surface in both solutions. Another phase, halite, crystallized at the beginning of the immersion in mod-DMEM owing to higher concentrations of 
$\mathrm{Na}^{+}$and $\mathrm{Cl}^{-}$ions (not only in comparison with I-solution but also with blood serum) and the presence of $\mathrm{Na}^{+}$ions released from the tested glass-ceramic scaffold. It has to be noticed that halite is not the residue of mod-DMEM or I-solution. The same treatment was applied on each glass-ceramic scaffold taken out from testing solutions (see Section 2.3.). The transmission geometry of the XRD measurement enabled finding the $\mathrm{NaCl}$ phase covered later by the precipitated $\mathrm{CaCO}_{3}$ phase. Probably, halite crystals served as advantageous sites for $\mathrm{CaCO}_{3}$ and ACP nucleation.

The presence of the organic components in mod-DMEM solution affects the rate of glass-ceramic dissolution; it is possible that the tested scaffold dissolved more slowly in modDMEM compared to I-solution: we estimated this based on small changes of $\mathrm{Ca}$ and $\mathrm{P}$ concentrations in the mod-DMEM leachates.

After completion of the test in I-solution the inert Pt spirals, in which the scaffold samples were suspended, were covered with a very thin layer. XRD analysis of the precipitate showed that the layer consisted mainly of the $\mathrm{NaCl}$ phase and $\mathrm{Ca}$ defective carbonate apatite (CDHA). This phenomenon had no influence on the conclusions of the present experiments but it should be discussed in the context of establishing a suitable setup and experimental conditions of bioactivity tests which is the matter of current work.

\section{Conclusions}

1. Non-buffered mod-DMEM solution is not the ideal environment for the formation of a hydroxyapatite phase in bioactivity tests of glass-ceramic material.

2. Exposure to non-buffered mod-DMEM and non-buffered Isolutions resulted in crystallization of calcite and precipitation of amorphous calcium phosphate (ACP) on the scaffold surface. 3. The organic part of mod-DMEM does not suppress crystallization of calcite, halite or precipitation of ACP; probably it suppresses the glass-ceramic dissolution.

4. Considering the general goal of monitoring the growth of hydroxyapatite phase (HAp) on the surface of materials as one of the important factors determining the so-called "bioactivity", a highly critical question remains to be answered related to the selection of the suitable buffering system to be commonly used for $\mathrm{SBF}$ and to the determination of appropriate in vitro test conditions.

\section{Acknowledgements}

This work was supported by the Technology Agency of the Czech Republic within the project TE01020390 Center for development of modern metallic biomaterials for medicinal implants. The authors would like to express their thanks for SEM/EDS analyses to Ing. Zuzana Zlámalová Cílová, $\mathrm{PhD}$, from the Department of Glass and Ceramics of the Institute of Chemical Technology in Prague. The authors would also like to thank Prof. Ing Jan Hlaváč, DrSc., professor emeritus, for his inspiring comments.

\section{References}

$1 \mathrm{~W}$. Cao and L. L. Hench, Bioactive materials, Ceram. Int., 1996, 22(6), 493-507.

2 ISO 23317, Implants for surgery - In vitro evaluation for apatiteforming ability of implant materials, 1st edn, 2007.

3 T. Kokubo and H. Takadama, How useful is SBF in predicting in vivo bone bioactivity?, Biomaterials, 2006, 27, 2907-2915.

4 P. N. De Aza, F. Guitan, A. Merlos, E. Lora-Tamayo and S. De Aza, Bioceramics-simulated body fluid interfaces: $\mathrm{pH}$ and its influence of hydroxyapatite formation, J. Mater. Sci.: Mater. Med., 1996, 7, 399-402.

5 H. Pan, X. Zhao, B. W. Darvell and W. W. Lu, Apatiteformation ability - predictor of "bioactivity"?, Acta Biomater., 2010, 6, 4181-4188.

$6 \mathrm{M}$. Bohner and J. Lemaitre, Can bioactivity be tested in vitro with SBF solution?, Biomaterials, 2009, 30, 2175-2179.

7 D. Rohanová, A. R. Boccaccini, D. M. Yunos, D. Horkavcová, I. Březovská and A. Helebrant, Tris buffer in simulated body fluid distorts the assessment of glass-ceramic scaffold bioactivity, Acta Biomater., 2011, 7, 2623-2630.

8 J. Hlaváč, D. Rohanová and A. Helebrant, The effect of Trisbuffer on the leaching behavior of bioactive glass-ceramics, Ceram.-Silik., 1994, 38, 119-122.

9 I. N. Bastos, G. M. Platt, M. C. Andrade and G. D. Soares, Theoretical study of Tris and bistris effects on simulated body fluids, J. Mol. Liq., 2008, 139(1-3), 121-130.

10 E. Z. Kurmaev, R. G. Wilks, R. Filby, A. Moewes, L. Müller and F. A. Müller, Characterization of chemically treated titanium using soft X-ray fluorescence, Mater. Sci. Eng., C, 2009, 29(1), 136-139.

11 L. Müller and F. Müller, Preparation of SBF with different $\mathrm{HCO}_{3}{ }^{-}$content ant its influence on the composition of biomimetic apatites, Acta Biomater., 2006, 2, 181-189.

12 S. Jalota, S. B. Bhaduri and A. C. Tas, Using a synthetic body fluid (SBF) solution of $27 \mathrm{mmol} \mathrm{dm}{ }^{-3} \mathrm{HCO}_{3}{ }^{-}$to make bone substitutes more osteointegrative, Mater. Sci. Eng., C, 2008, 28, 129-140.

13 V. Cannillo, F. Pierli, I. Ronchetti, C. Siligardi and D. Zaffe, Chemical durability and microstructural analysis of glasses soaked in water and in biological fluids, Ceram. Int., 2009, 35, 2853-2869.

$14 \mathrm{~S}$. Mandel and A. C. Tas, Brushite $\left(\mathrm{CaHPO}_{4} \cdot 2 \mathrm{H}_{2} \mathrm{O}\right)$ to octacalcium phosphate $\left(\mathrm{Ca}_{8}\left(\mathrm{HPO}_{4}\right)_{2}\left(\mathrm{PO}_{4}\right)_{4} \cdot 5 \mathrm{H}_{2} \mathrm{O}\right)$ transformation in DMEM solutions at $36.5{ }^{\circ} \mathrm{C}$, Mater. Sci. Eng., C, 2010, 30, 245-254.

15 J. Faure, A. Balamurugan, H. Benhayoune, P. Torres, G. Balissier and J. M. F. Ferreira, Morphological and chemical characterisation of biomimetic bone like apatite formation on alkali treated Ti6Al4V titanium alloy, Mater. Sci. Eng., C, 2009, 29, 1252-1257.

16 V. Aina, G. Malavasi, A. Fiorio Pla, L. Munaron and C. Morterra, Zinc-containing bioactive glasses: surface reactivity and behaviour towards endothelial cells, Acta Biomater., 2009, 5, 1211-1222. 
17 G. Theodorou, O. M. Goudouri, E. Kontonasaki, X. Chatzistavrou, L. Papadopoulou, N. Kantiranis and K. M. Paraskevopoulos, Comparative bioactivity study of $45 \mathrm{~S} 56$ and $58 \mathrm{~S}$ bioglasses in organic and inorganic environment, Bioceramics edit. Kim Sukyoung, 2009, 22, 391-394.

18 M. A. Miller, R. M. Kendal, K. J. Manoj, P. R. Larson, A. S. Madden and A. C. Tas, Testing of Brushite $\left(\mathrm{CaHPO}_{4} \cdot 2 \mathrm{H}_{2} \mathrm{O}\right)$ in Synthetic Biomineralization Solutions and In Situ Crystallization of Brushite Micro-Granules, J. Am. Ceram. Soc., 2012, 95(7), 2178-2188.

19 N. Temizel, G. Girisken and A. C. Tas, Accelerated transformation of brushite to octacalcium phosphate in new biomineralization media between $36.5{ }^{\circ} \mathrm{C}$ and $80{ }^{\circ} \mathrm{C}$, Mater. Sci. Eng., C, 2011, 31, 1138-1143.

20 Q. Z. Chen, L. D. Thompson and A. R. Boccaccini, 45S5 Bioglass-derived glass-ceramic scaffolds for bone tissue engineering, Biomaterials, 2006, 27, 2414-2425.
21 A. Helebrant, L. Jonášová and L. Šanda, The influence of simulated body fluid composition on carbonated hydroxyapatite formation, Ceram.-Silik., 2002, 46(1), 9-14.

$22 \mathrm{X}$. Lu and Y. Leng, Theoretical analysis of calcium phosphate precipitation in simulated body fluid, Biomaterials, 2005, 26(10), 1097-1108.

23 JCPDS-ICDD PDF-2 database, International Centre for Diffraction Data, Newtown Square, PA, U.S.A. release 54, 2004.

24 A. C. Tas, X-ray-amorphous calcium phosphate (ACP) synthesis in a simple biomineralization medium, J. Mater. Chem. B, 2013, 1, 4511-4520.

25 D. Rohanová, D. Horkavcová, A. R. Boccaccini, I. Březovská, P. Bozděchová, P. Bezdička, M. Častorálová and A. Helebrant, Interakce sklokeramického "scaffoldu" připraveného ze skla Bioglass® ${ }^{\circledR}$ se simulovanými tělnými tekutinami, Sklár a keramik, C, 2011, 61, 125-128. 